Research Article

\title{
Assessment of Knowledge of Student Nurses regarding Use of Simulation: A Modern Learning Approach in Nursing
}

\author{
Merlin Mary James', Jahanara Rahman ${ }^{2}$ \\ 1,2Tutor, Rufaida College of Nursing, Jamia Hamdard, New Delhi, India. \\ DOI: https://doi.org/10.24321/2455.9318.201930
}

\section{I $\quad \mathbf{N} \quad \mathbf{F} \quad \mathbf{O}$}

\section{Corresponding Author:}

Merlin Mary James, Rufaida College of Nursing, Jamia Hamdard, New Delhi, India.

E-mail Id:

merlinjames1988@yahoo.com

Orcid Id:

https://orcid.org/0000-0001-9496-983X

How to cite this article:

James MM, Rahman J. Assessment of Knowledge of Student Nurses regarding Use of Simulation: A Modern Learning Approach in Nursing. Int J Nurs Midwif Res 2019; 6(4): 34-38.

Date of Submission: 2019-09-18

Date of Acceptance: 2020-02-26

\section{$\begin{array}{llllllll}\mathbf{A} & \mathbf{B} & \mathbf{S} & \mathbf{T} & \mathbf{R} & \mathbf{A} & \mathbf{C} & \mathbf{T}\end{array}$}

Introduction: The use of simulation as teaching methodology is becoming increasingly prevalent in healthcare practice and there is an increased and widespread use of simulation as a learning approach.

Objective: The present study is aimed at assessing the knowledge of student nurses' regarding the use of simulation as a learning approach.

Materials and Methods: Descriptive research design was used to assess the knowledge of 34 student nurses selected using convenient sampling technique, studying in Rufaida College of Nursing, Jamia Hamdard. A structured questionnaire was developed to assess the knowledge of student nurses regarding simulation and data was analyzed using descriptive statistics.

Result: The study findings revealed only $8.82 \%$ of student nurses were having above average knowledge regarding simulation, majority (52.94\%) of them were having average knowledge and $38.23 \%$ were having below average knowledge regarding simulation as a learning approach.

Conclusion: Student nurses are future health care workers and need to understand about the importance of simulation as a modern learning approach. There is an absolute dearth of implementing novice educational tools and total dependence of traditional teaching methodology, which is to some extent reducing the learning capacity of the current generation as it is non-aligned with the rapidly progressing technology. Teachers need to embrace newer educational tools to ensure improvement in knowledge retention and skill building of student nurses, thereby ensuring patient safety.

Keywords: Simulation, Student Nurses, Teaching Methodology

\section{Introduction}

Nursing education is characterized by being a professional field of study, meaning that it is vocationally oriented and qualifies for the exercises of specialized services. ${ }^{1,2}$
In order to act professionally as a nurse, it is important that her knowledge is scientifically based and she has the requisite practical skills and professional judgement, and in addition personal qualities, attitudes and values..$^{2,3}$ 
Errors might possibly be linked to individual competence, team performance, properties of health personnel's tools, operating environment and tasks; whereas, safety improvement comes from understanding and influencing these connections. ${ }^{4}$ In order for the student nurses to be competent in applying practical skills and professional judgement, the nursing education need to focus on helping the students to apply classroom learning in a clinical context to enhance patient safety and not inflicting harm on them. In order to ensure safe clinical practice, simulation-based training has rapidly expanded. There is a need for change in nursing education to help facilitate students to transfer theoretical knowledge into a clinical context, thereby addressing content - context mismatch.

$\mathrm{Gaba}^{5}$ describes simulation as a technique that can be used to replace or amplify real experiences with guided experiences that evoke or replicate substantial aspects of the real world in a fully interactive manner. Simulation can be outlined as continuum from Low-Fidelity Simulation (LFS) to high fidelity simulation (HFS). ${ }^{6}$

The first recorded use of a medical simulator is that of a mannikin created in the $17^{\text {th }}$ century by Dr. Gregoire of Paris. He used a pelvis with skin stretched across it to simulate abdomen and with the help of a dead fetus explained assisted and complicated deliveries to midwives. ${ }^{7}$

Simulation as a teaching methodology helps student nurses to improve their confidence and competence, thereby improving patient safety and reduction in medical errors.

The patients have the right to be cared by professional, caring, and experienced nurses who have protective dispositions and the ability to safeguard patient safety through both their own actions and the actions of others. Such dispositions and abilities must be developed and cultivated during education in order to be able to identify the evident or tacit claim that emerge in the encounter with the patient and to take a stand on how to prioritize and act in accordance with the patients' needs. There is a need for changes in nursing education to help facilitate students to transfer theoretical knowledge into a clinical context, and to develop the necessary personal abilities. ${ }^{8}$

The optimal learning in nursing is conceived to be, as in participation, in interaction with patients and in the nursing community, by transferring the abstract universal, in a uniquely particular situation. However, a prerequisite for this learning is to understand the situation, to recognize and obtain relevant knowledge for the current situation and to have a basis to work from. However, it is not obvious for a student to understand or perceive the rationale for how the situation is to be solved, and tacit or implied knowledge might be difficult to grasp for a novice. ${ }^{8}$

Randi $\mathrm{T}^{8}$ conducted a quantitative and qualitative study on simulation used as a learning approach in nursing, which was carried out at Faculty of Health Science and Technology Nursing Science, Karlstad University Studies. The overall aim of the thesis was to investigate bachelor nursing students' experiences with simulation as a learning approach conducted under various conditions. Additionally, the aim was to translate and validate questionnaires for the evaluation of simulation in a Norwegian context. Nursing students $(n=86)$ representing different educational levels responded to three questionnaires, the student satisfaction and self-confidence in learning, the educational practices questionnaire and the simulation design scale, after attending either low or high-fidelity level simulation in a scenario developed for a specific educational level. The results of the study were independent of the fidelity level in the simulation and educational levels. The students reported satisfaction and that the emphasized features in learning were present. The conclusion of the study was that simulations at all levels of fidelity can be used in nursing education.

Nursing students are educated in two separate and independent organizations, each with their own primary function area; the faculty has teaching and learning in focus, whereas the clinic primarily focuses on the care and treatment of patients. The students should ideally bring acquired theoretical knowledge into the encounter with the patient, while in opposite direction, experiences and knowledge achieved in the clinic should be brought back to the faculty for further learning. However, the transformation of knowledge from theory into practice and previously achieved knowledge and experiences to be recontextualized on new arenas is not an easy process. The separation of theory and practice causes challenges for ensuring the quality of study, often referred to as "the theory-practice gap". ${ }^{8}$

There is a need for the nursing education system to address this theory - practice gap by focussing on helping the students to apply the classroom learning in a clinical context to ensure quality of patient care and enhance patient safety. In India, there is a dearth of research evidence showing the knowledge of student nurses regarding simulation as a learning tool, however, on the contrary there is an increased and widespread use of simulation as a learning approach.

In India, it should be made as a mandatory prerequisite for the student nurses to achieve learning by assessing their simulation competency and this is also essential for a positive learning outcome. Using simulation, a learning approach will enable the student nurses in problem solving and ensure improved willingness to participate actively. Simulation will also ensure a good learning environment, thereby addressing to the theory - practice gap. Although simulation may pose some challenges, like infrastructure, 
resource availability, trained facilitators and facilitator's ability to conduct the session, yet once the outcomes of simulation learning are identified, nothing can deter the nursing education system to implement the same.

One such example, is the pre-service training on maternal and child health, being rendered at National Skills Training Centre - "Daksh", Jamia Hamdard, New Delhi, India. All the students are trained on low to high fidelity simulators and during the sessions, the student nurses are allowed to practice to improve their skills. This methodology of teaching - learning process have proved beneficial in improving the skills of the student nurses. There is limited evidence about how simulation can be implemented in nursing education.

The student nurses still lack knowledge regarding simulation as learning tool and hence, a need was felt to assess the knowledge of student nurses regarding use of simulation as a learning approach.

\section{Objective of the Study}

To assess the knowledge of student nurses regarding use of simulation as a learning approach.

\section{Materials and Methods}

A quantitative non experimental research approach using descriptive research design was used to attain the objective of the study. The present study was conducted in Rufaida College of Nursing, School of Nursing Sciences and Allied Health, Jamia Hamdard for a period of two weeks and population comprised of student nurses. The sample for the present study was 34 students pursing Post Basic B.Sc. Nursing selected through convenient sampling technique. The students who were willing for participation and present during the data collection were included in the study. Informed consent was sought from the samples before collecting data. For data collection, a structured knowledge questionnaire was developed based on extensive review of literature, opinion of experts and informal discussions with peer groups. The tool was validated by 7 experts from the nursing field using content validity. The tool was found to be reliable. A formal permission was sought from the Principal, Rufaida College of Nursing, School of Nursing Sciences and Allied Health, Jamia Hamdard. Ethical approval was sought from the Institutional Review Board of Jamia Hamdard. Pilot study was conducted on 10 student nurses from DGNM course studying in Rufaida College of Nursing. The data entered in excel sheets and was analyzed using descriptive statistics.

\section{Result}

\section{Findings related to the Demographic Profile of the Student Nurses}

Frequency and percentage of the student nurses were computed by their age, religion and any pre - service program on simulation attended previously, (Table 1).

Table I.Frequency and percentage of demographic profile of student nurses

\begin{tabular}{|c|c|c|c|}
\hline $\begin{array}{l}\text { S. } \\
\text { No. }\end{array}$ & Demographic profile & $\begin{array}{c}\text { Frequency } \\
\text { (f) }\end{array}$ & $\begin{array}{c}\text { Percentage } \\
(\%)\end{array}$ \\
\hline \multirow{4}{*}{1.} & Age (in years) & & \\
\hline & Below 24 & 14 & 41.7 \\
\hline & $24-26$ & 16 & 47.05 \\
\hline & $27-30$ & 4 & 11.76 \\
\hline \multirow{3}{*}{2.} & Gender & & \\
\hline & Male & 01 & 2.94 \\
\hline & Female & 33 & 97.05 \\
\hline \multirow[t]{3}{*}{3.} & $\begin{array}{l}\text { Any pre-service } \\
\text { program on attended } \\
\text { previously on } \\
\text { simulation }\end{array}$ & & \\
\hline & Yes & 20 & 58.82 \\
\hline & No & 14 & 41.17 \\
\hline
\end{tabular}

\section{Findings related Knowledge Scores of Student Nurses regarding Simulation as a Learning Approach}

The knowledge scores of the student nurses were categorized as below average, average and above average. Mean, median and standard deviation of knowledge scores of student nurses were also computed, (Table 2), (Figure 1).

Table 2.Category of knowledge scores of student nurses

\begin{tabular}{|c|c|c|c|}
\hline $\begin{array}{c}\text { Category of } \\
\text { Knowledge } \\
\text { Scores }\end{array}$ & $\begin{array}{c}\text { Range of } \\
\text { Knowledge } \\
\text { Scores }\end{array}$ & $\begin{array}{c}\text { Frequency } \\
\text { (f) }\end{array}$ & $\begin{array}{c}\text { Percentage } \\
\text { (\%) }\end{array}$ \\
\hline Below Average & $0-8$ & 13 & 38.23 \\
\hline Average & $9-16$ & 18 & 52.94 \\
\hline Above Average & $17-20$ & 3 & 8.82 \\
\hline
\end{tabular}

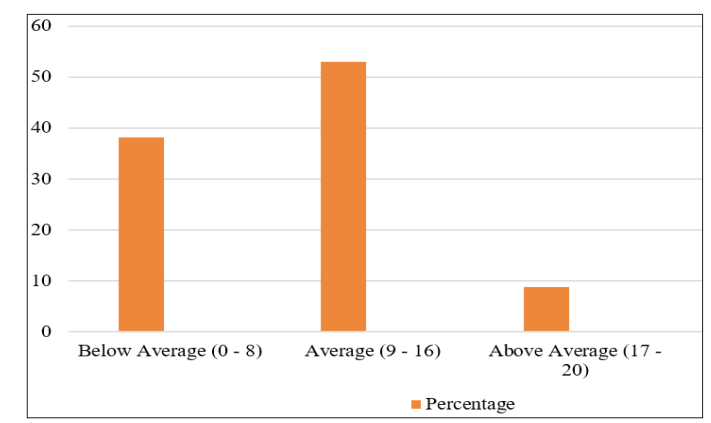

Figure I.A Bar diagram depicting the categories of knowledge scores of student nurses regarding simulation as a learning approach 
The data presented in Table 2, shows that only $8.82 \%$ of student nurses were having above average knowledge regarding simulation, more than half $(52.94 \%)$ of them were having average knowledge and $38.23 \%$ were having below average knowledge as a learning approach.

Table 3.Mean, median, standard deviation, possible range of scores and obtained range of knowledge scores of student nurses

\begin{tabular}{|c|c|c|c|c|}
\hline $\begin{array}{c}\text { Possible } \\
\text { range of } \\
\text { scores }\end{array}$ & $\begin{array}{c}\text { Obtained } \\
\text { range of } \\
\text { scores }\end{array}$ & Mean & Median & $\begin{array}{c}\text { Standard } \\
\text { Deviation }\end{array}$ \\
\hline $0-20$ & $3-18$ & 9.97 & 9 & 4.74 \\
\hline
\end{tabular}

The data presented in Table 3 shows that the mean knowledge score was 9.97, with a median of 9 and a standard deviation of 4.47 .

\section{Discussion}

Learning by doing is the principle of simulation and student nurses using simulation as a learning approach will exceed their ability to cope with challenges in a safe and controlled environment, thereby improving their self confidence levels.

The findings of the present revealed that that only $8.82 \%$ of student nurses were having above average knowledge regarding simulation, majority (52.94\%) of them were having average knowledge and $38.23 \%$ were having below average knowledge as a learning approach. The study findings are aligned with the study conducted by Evans CB and Mixon DK to assess undergraduate nursing students' pain knowledge after participation in a simulation scenario. The Knowledge and Attitudes of Survey Regarding Pain (KASRP) was used to assess pain knowledge. Undergraduate nursing students' knowledge of pain management is reported as inadequate. ${ }^{9}$

The present study findings suggest that there is emerging need to incorporate simulation as teaching methodology and learning approach, to educate undergraduate nurses in a safe and controlled environment.

\section{Recommendation}

- The study recommends the need for the following:

- To conduct a research to analyze the relationship between simulation based learning and students' self-confidence.

- To analyze the patient outcome as a result of learning from simulation.

- To investigate how simulation competency can be achieved when there is a large student - teacher ratio.

- To investigate how the learning approaches used in simulation can be integrated into the curriculum.

\section{Conclusion}

The major conclusions drawn from the study are:
- The student nurses need to imbibe simulation as a learning approach to improve their self-confidence.

- Student nurses are future health care workers and need to understand about the importance of simulation as a modern learning approach.

- There is an absolute dearth of implementing novice educational tools and total dependence of traditional teaching methodology, which is to some extent reducing the learning capacity of the current generation as it is non-aligned with the rapidly progressing technology.

- Active learning approaches must integrate generally into the nursing education.

- There is heightened need to enhance the focus on patient safety in nursing education and this can be achieved by implementing learning in safe and controlled environment.

- Teachers need to embrace the newer educational tools to ensure improvement in knowledge retention and skill building of student nurses, thereby ensuring patient safety.

\section{Conflict of Interest: None}

\section{References}

1. Profesjonsstudier II. Retrieved from: https://www. universi tetsforlaget.no/nettbutikk/profesjonsstudierii-uf.html.

2. Profesjonsstudier. Retrieved from: https://www. universitets forlaget.no/nettbutikk/profesjonsstudieruf.html.

3. Cody WK. Philosophical and Theoretical Perspectives for Advanced Nursing Practice. $5^{\text {th }}$ edition. Jones and Bartlett, Burlington, MA. 2013. Available from: https://journals. sagepub.com/doi/abs/10.1177/0894318413477151.

4. Sidney D. Patient safety: a human factors approach. CRC Press Boca Raton. Taylor and Francis Group, 2011. Available from: https://www.crcpress.com/ Patient-Safety-A-Human-Factors-Approach/Dekker/p/ book/9781439852255.

5. Gaba DM. The future vision of simulation in health care. Quality and Safety in Health Care 2004; 13(1): 2-10. Available from: https://qualitysafety.bmj.com/ content/13/suppl_1/i2.long [PubMed/Google Scholar].

6. Hovancsek MT. Using Simulations in Nursing Education. In PR Jeffries (Ed.). Simulation in Nursing Education: from Conceptualization to Evaluation. National League for Nursing, New York. 2007; 1-9.

7. Abbas OA, Samuel BO, Odufeko GT. Medical simulation a tool yet untapped in most developing nations in Africa. International Journal of Computer Applications 2014; 97(5): 1-4. Available from: https://pdfs.semanticscholar. org/1fb7/3f18bce5a28b372c258f3898535727d48d91. pdf.

8. Randi T. Simulation used as a learning approach in 
nursing education. Dissertation. Karlstad University studies. 2015: 1. Available from: https://www.divaportal.org/smash/get/diva2:760893/FULLTEXT01.pdf.

9. Evans CB, Mixon DK. The evaluation of undergraduate nursing students' knowledge of post-op pain management after participation in simulation. Pain Management Nursing Journal 2015; 16(6): 930-937. Available from: https://www.sciencedirect.com/ science/article/abs/pii/S1524904215001174 [PubMed/ Google Scholar]. 